\title{
Low profile Substrate Integrated Waveguide (SIW) wideband antenna for Ku-band Applications
}

\author{
Faris Mohammed Ali ${ }^{1}$, Ahmed Ghanim Wadday ${ }^{1}$, Aseel Hameed Al_Nakkash ${ }^{2}$, Ali Najah Al-Shamani ${ }^{1}$ \\ fanmnm2018@gmail.com \\ ${ }^{1}$ Department of Communications Techniques Engineering, Engineering Technical College, Al-Furat Al- \\ Awsat Technical University, Al-Najaf 31001, Iraq \\ ${ }^{2}$ Middle Technical University/ Electrical Technical Engineering College, Iraq
}

\begin{abstract}
For wireless applications, a low-profile circular slot with a substrate integrated waveguide (SIW) antenna is given. For bandwidth augmentation, the proposed antenna structure consists of a microstrip antenna with two circular-shape slots etched on the top of the radiation plane and stacked one on top of the other. An FR-4 substrate with a dielectric constant of 4.3 and a thickness of $1.5 \mathrm{~mm}$ was used to create this antenna. The optimised antenna design has a $13.2 \mathrm{GHz}$ operating frequency, a 4.913 percent bandwidth, and a peak gain of roughly $6.05 \mathrm{~dB}$ over the operating frequency, making it appropriate for wireless communication applications with good matching characteristics. CST Microwave Studio is used to compute the design model and performance evaluation of a proposed antenna..
\end{abstract}

Keywords: Wideband, low profile, a slot antenna vias, substrate integrated waveguide (SIW)

\section{Introduction}

In recent years, wireless communication systems which operate at microwave frequencies have evolved rapidly, where this area attracted many industrial and academic fields $[1,2,3,4]$. substrate integrated waveguides SIWs technology has been replaced the conventional transmission lines over the old ones due to its desirable propagation characteristics and simple construction [5]. SIW technology has been introduced as one of the techniques available to provide low-cost implementation such as waveguide Components by using a standard PCB printed circuit board [6,7], (SIW) have many advantages over conventional bulky metallic counterparts, such as low cost, small size and easy manufacturing along with the difficult characteristics of the waveguide including high power handling capability and low insertion losses and integration with planar circuits [8,9]. SIW configuration is a mixture of dielectric material embedded in linear arrays of metal vias along with upper and lowest conductive surfaces [10,11,12].

Cassivi et al. were the first to present a substrate integrated waveguide cavity, which was implemented in a planar substrate using four rows of metallic vias [13]. Later The SIW technique has been used for designing and fabrication filters and slot antennas $[14,15,16,17]$. low profile designs antenna are achieved by using SIW technique for high gain and wideband [18, 19, 20, 21]. Impedance bandwidth was improved to up to $13.89 \%$ with moderate gain and unidirectional radiation characteristics in [22].

In this study, substrate integrated waveguide technology is applied to a traditional microstrip antenna with two circular slots etched on the antenna's top metallic surface for satellite applications. The classic rectangular waveguide, with SIW's periodic metallic vias serving as the standard waveguide's sidewall. As a result, this study presents a SIW antenna with two circular slots, which corresponds to a filling dielectric rectangular waveguide with two etched slots cut in the top wall of the waveguide [23].

\section{SIW Microstrip Antenna Design Procedure}

As illustrated in Fig.1, the SIW antenna is made by sandwiching two conductive layers between dielectric substrates that are connected on both sides by cylindrical metallic array vias and activated with inset feeding. 


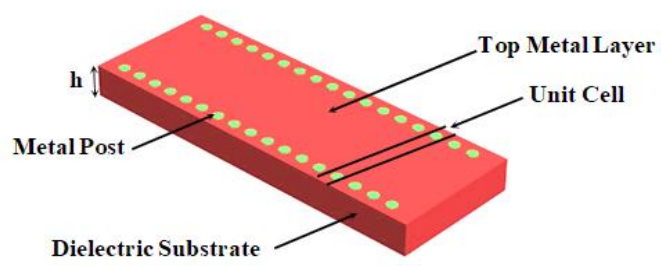

Fig. 1. SIW structure

The SIW's operating principle contains the artificial channel to Guiding the Wave inside the substrate. This is achieved by drilling the metal vias on the substrate that function as side walls to SIW structure Fig. 2 The SIW structured by choosing suitable dielectric material and that Just at the beginning of the antenna design stage should be considered taking into account parameters such as antenna bandwidth, size, gain, impedance matching, etc. and other Structure requirements.

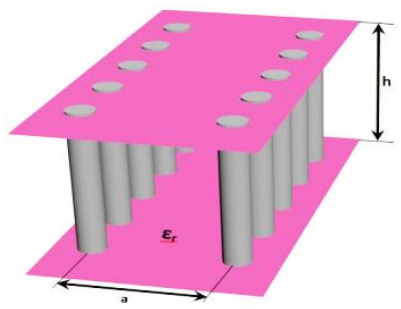

Fig. 2. SIW structure (conventional rectangular waveguide)

At the beginning, the dimensions of The antenna with microstrip patch in Fig. 3 A patch length (Lp) and patch width (Wp) can be obtained by equations below. [24] .

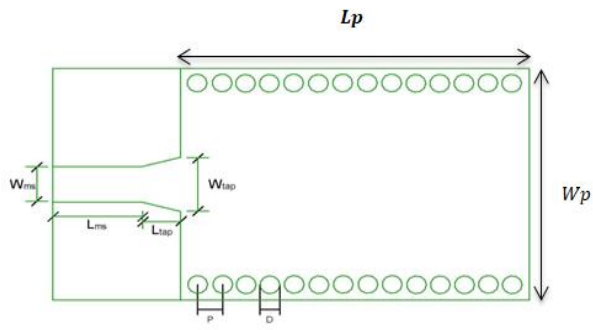

Fig. 3. Design geometry of the SIW antenna

Where

$w p=\frac{c}{2 f_{o} \sqrt{\frac{\left(\epsilon_{r}+1\right)}{2}}}$

$l p=\frac{c}{2 f_{o} \sqrt{\epsilon_{\text {reff }}}}-2 \Delta l$

C: Light speed within free space.

$f_{o}$ : The frequency of resonances.

$\epsilon_{r}$ : The substrate dielectric constant.

$\Delta \mathrm{L}$ : the extended increase of patch length

Can measure the effective dielectric constant as:

$\epsilon_{\text {reff }}=\frac{\epsilon_{r}+1}{2}+\frac{\epsilon_{r}-1}{2}\left[1+12 \frac{h}{w}\right]^{\frac{1}{2}}$

$\epsilon_{r}$ : Dielectric constant of the substrate. 
$\epsilon_{\text {reff }}:$ Effective dielectric constant.

h: thickness of dielectric substrate.

w: the patch the width.

SIW's calculations include numbers of design equations and their design rules to ensure minimal losses from leakage between metalized via gaps in the structure of SIW [6]. Effects of p (pitch: distance between two vias) and d (diameter of hole) on those difficulties were explored in order to ensure that the waveguide section becomes free of leakage loss or radiation less [25].

$$
\begin{gathered}
d<\frac{\lambda_{g}}{5} \\
p \leq 2 d
\end{gathered}
$$

$\lambda g:$ Waveguide wavelength.

So, the cut off frequency (fc) of arbitrary mode for a rectangular waveguide, is found by the following formula:

$f c=\frac{c}{2 \pi} \sqrt{\left(\frac{m \pi}{a}\right)^{2}+\left(\frac{n \pi}{b}\right)^{2}}$

$\mathrm{a}, \mathrm{b}$ : dimensions of the waveguide.

$\mathrm{m}, \mathrm{n}$ : number of modes.

At fundamental mode, this can be simplified by:

$f c=\frac{c}{2 a}$

For Dielectric filled waveguide width at the similar cut off frequency, dimension "ad" is given by:

$a_{d}=\frac{a}{\sqrt{\epsilon_{r}}}$

We can now proceed to the SIW design equations after determining the dimension "a" for the Dielectric filled waveguide:

$w=a_{d}+\frac{d^{2}}{0.98 p}$

Where d: diameter of via.

p: pitch (distance between two vias)

$w=a_{d}-1.08 \frac{d^{2}}{p}+0.1 \frac{d^{2}}{a_{d}}$

The SIW structure can be presented as simply rectangular waveguide as shown in Fig. 2 through the so-called equivalent width $a_{e q}$. This is stated as:

$a_{e q}=\operatorname{asiw}-\frac{d^{2}}{0.95 p}$

$l_{\text {eff }}=l_{\text {siw }}-\frac{d^{2}}{0.95 p}$

\section{The Proposed Antenna Configuration}

The proposed SIW antenna construction has overall dimensions of $35 \mathrm{mmx} 18 \mathrm{~mm}$ and was developed as a single layer on FR-4 substrate with a relative permittivity of $\varepsilon r=4.3$, loss tangent of $=0.025$, and a thickness of $\mathrm{h}=1.5 \mathrm{~mm}$. It is fed by a $50 \Omega$ microstrip line. $1.08 \mathrm{~mm}$ and $1.20 \mathrm{~mm}$ are the diameter and period of the metallic via, respectively. $15.8 \mathrm{~mm}$ is the equal distance between two rows of metallic vias. Equations (11) - (13) are used to calculate the SIW cavity dimensions (12). The suggested SIW antenna's geometry is depicted in Fig. 4, and the overall antenna dimensions are listed in Table 1.

Table 1: Parameter and dimension of SIW radiator. 


\begin{tabular}{ll}
\hline Parameter Values (mm) & Parameter Values (mm) \\
\hline The total length (L) & 35 \\
The total width (W) & 18 \\
Via's diameter (D) & 1.08 \\
Pitch between two vias (P) & 1.20 \\
Equavelent width of SIW (Asiw) & 15.8 \\
Microstrip Width (Wms) & 1.56 \\
Microstrip Length (Lms) & 3.10 \\
Taper 's width (Wtap) & 3.58 \\
Taper's length (Ltap) & 4.90 \\
Diamrter of circular slot(Dc) & 12.5 \\
Width of circular slot(Wc) & 0.5 \\
Distance between slots(S) & 2 \\
\hline
\end{tabular}

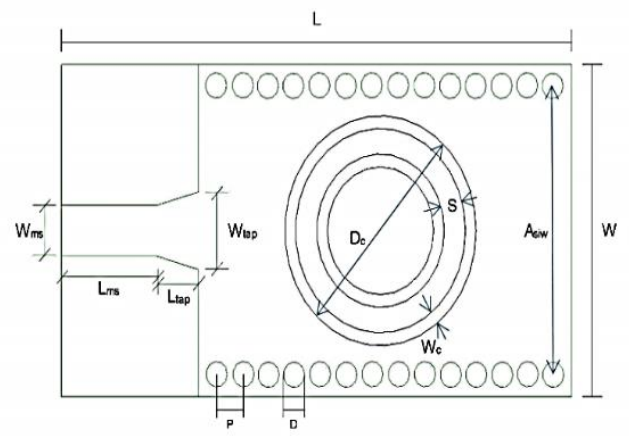

Fig. 4. Geometry of the proposed antenna

\section{Results and Discussion}

To assess and compare our results, we developed the first proposed antenna without SIW and slot, as shown in Fig. (5a). The antenna was created using the specified substrate. As illustrated in Fig. (5b), the antenna gives a single band resonance within the sweep frequency range of (9-20) GHz, with a resonant frequency of around $10 \mathrm{GHz}$. However, this behaviour does not rule out the potential of other resonances occurring outside of this frequency range.

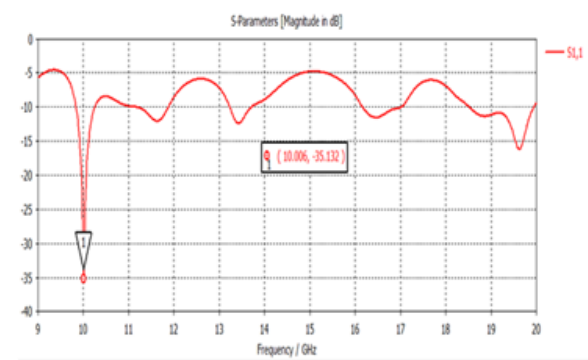

(a)

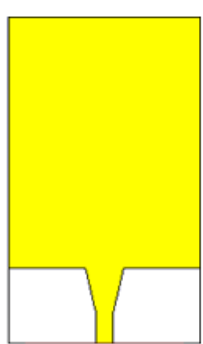

(b)

Fig. 5:(a) geometry of first proposed antenna (b) Simulated return loss response of antenna without SIW

Fig. 6 illustrates the computed two-dimensional directivity patterns of this antenna. The measured omnidirectional directivity is $8.8 \mathrm{~dB}$ with a peak gain $2.07 \mathrm{~dB}$ and fractional bandwidth $(4.1 \%)$. 
Farfield Directivity Abs (Phi=90)

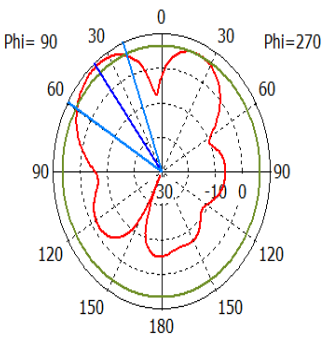

Theta / Degree vs. dBi

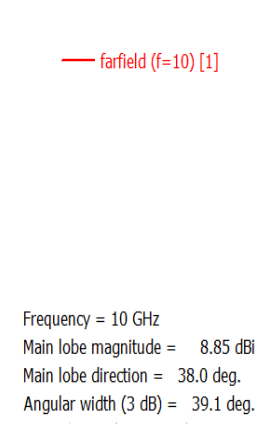

Farfield Gain Abs (Phi=90)

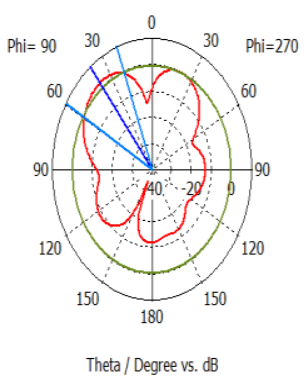

— farfield ( $\mathrm{f}=10)[1]$

Frequency $=10 \mathrm{GHz}$

Main lobe magnitude $=2.07 \mathrm{~dB}$

Main lobe direction $=38.0$ deg. Angular width $(3 \mathrm{~dB})=39.1 \mathrm{deg}$.

Fig. 6 simulated two-dimensional directivity radiation patterns

From the results, it was found that the proposed antenna doesn't satisfy the goal of frequency band, gain and bandwidth requirements for satellite applications, to achieve antenna match with Ku-band range application and satisfy these requirements, SIW antenna has accomplished. Where, SIW technique is applied with prescribed calculated dimensions of via and equivalent distance between vias to enhance the bandwidth and gain. Circular slot is added to increase the bandwidth, directivity, gain, and enhance the antenna matching. After executed above procedure, the proposed SIW antenna for one, two and three circular slot have done as shown in Fig. 7 (a to d).

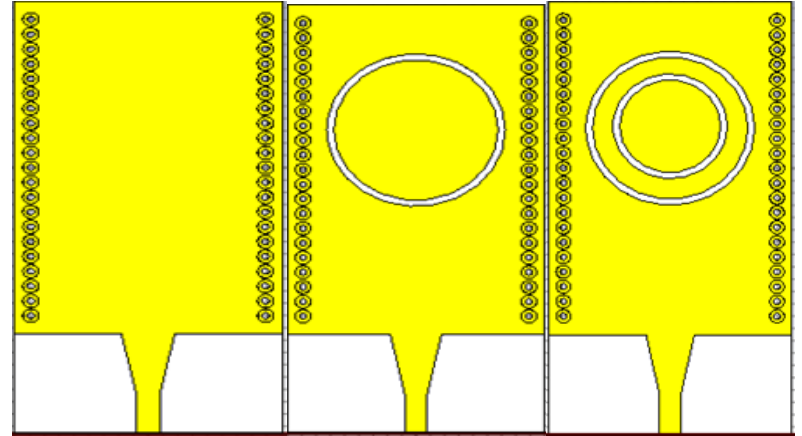

(a) (b)

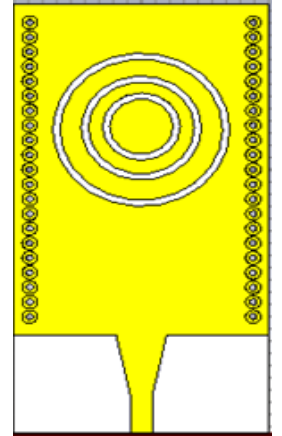

(d)

Fig. 7: (a) SIW antenna without slots, (b) SIW with one circular slot.

(c) SIW with two circular slot. (d) SIW antenna with three circular slot.

The result in Fig. 7a shows that, when SIW applied on the conventional microstrip antenna, the antenna gives two resonant frequencies (14.8 and 19.22) GHz. Where the upper resonant frequency can satisfy the requirement range with peak directivity of ( 8.43 and 9.74) $\mathrm{dBi}$, respectively for two resonance. As well as, the gains and bandwidth are (2.99 and 2.26) $\mathrm{dB},(1.086 \%$ and $1.349 \%) \mathrm{GHZ}$ respectively. Fig. 8 show the directivity and gain of the two resonance frequencies in polar form for the antenna shown in Fig. (7a).

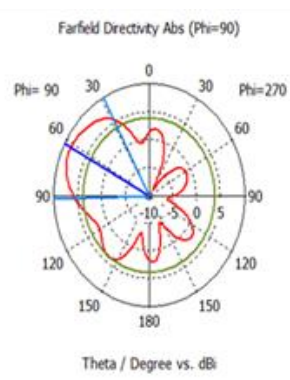

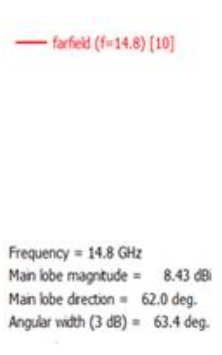

Man bbe magrtude $=8.43$ dis Angular woth $(3 \mathrm{~dB})=63.4 \mathrm{deg}$.

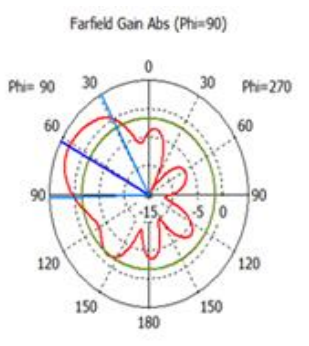

Theta / Degree vs, dB

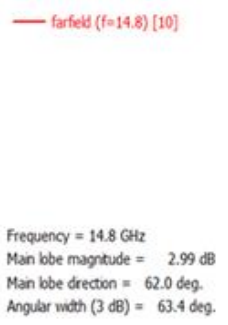




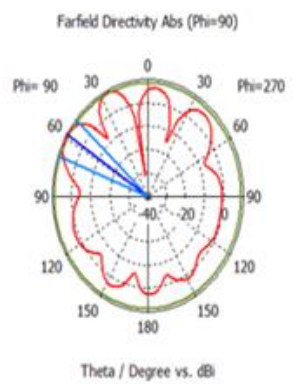

Thera / Degee rs.

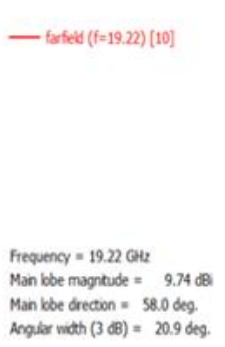

Angiar with $(3 \mathrm{~dB})=20.9 \mathrm{deg}$.

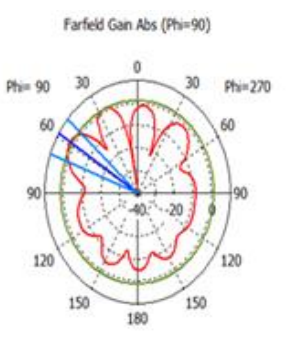

Thera / Degee vs. 88
- tarfed (fo-19.22) [10]

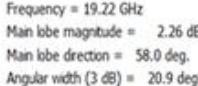

Angiar wath $(30)=20.0$ deg.

Fig. 8 directivity and gain of SIW antenna without slots for(14.8 and 19.22) GHz

While, Fig. $7 \mathrm{~b}$ shows that when etched one circular slot on the one top of the antenna gives three resonant frequencies which are $(11.20,13.18,19.53) \mathrm{GHz}$, the middle is at the required range, the peak directivities are $(7.66,8.34,10.1) \mathrm{dBi}$, respectively for $(13.18) \mathrm{GHz}$. While the peak gain for the triple-band is $(4.74,5.53$, $3.44) \mathrm{dB}$ with fractional bandwidth about $(502,1.001,3)$ respectively. Fig. 9 show the directivities and gains of SIW one slot antenna in polar form.
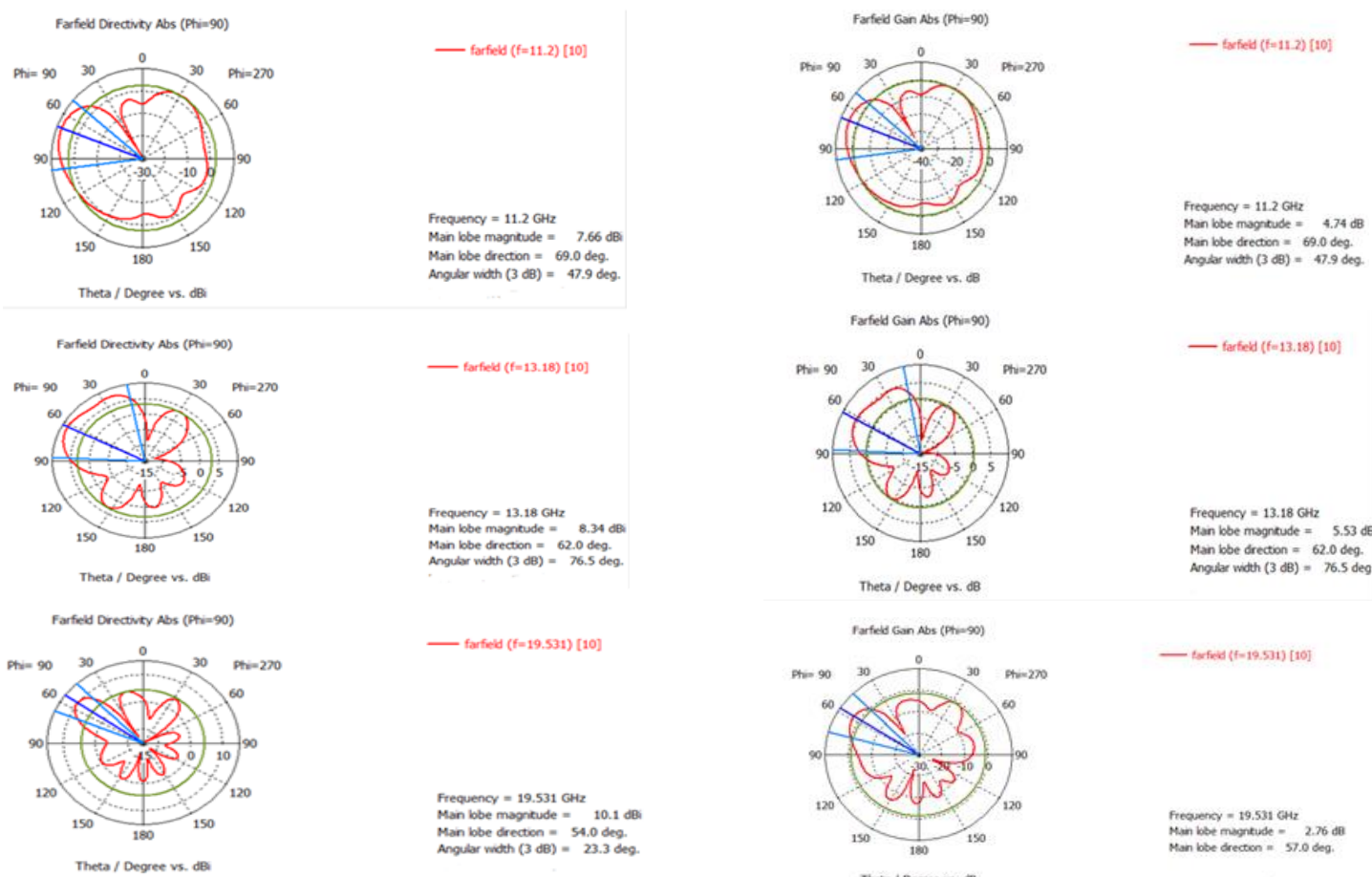

Farfed Gan Abs (\$hin=90)

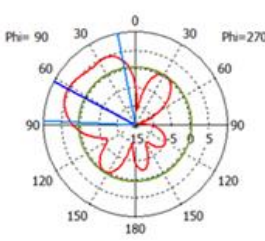

— farted (f $f=13.18)(10]$

Theta / Degree vs. de

Frequency $=13.18 \mathrm{GHz}$ Man bebe drection $=62.0 \mathrm{deg}$.

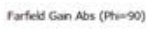

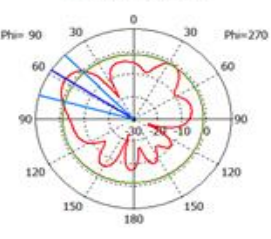

— toffed (t-19.51) [10]

Thesa / Depree va di

Fig. 9 Directivities and gains of SIW radiator with one circular slot

Meanwhile, results of the SIW radiator with two slot shows that etched two circular slots on the one top of the antenna give one resonant frequency about (13.2) GHz which is the required range. The directivity and gain are (8.56) (6.06) dB with a bandwidth about (4.913) GHZ. Fig. 10 shows the directivity and gain in polar form.
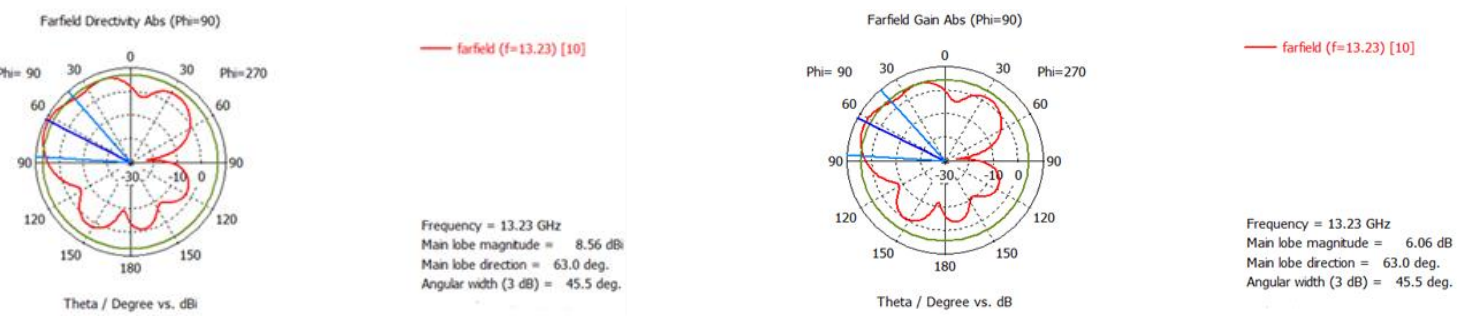
Fig. 10. Directivities and gains of SIW antenna with two circular slot

Finally, when the third slot is included the frequency is still about (13.2) GHz is in the required range, the directivity is $8.78 \mathrm{dBi}$, the gain is $6.28 \mathrm{~dB}$ with a bandwidth of about (3.568) GHz. Fig. 11 shows the directivity and gain in polar form.
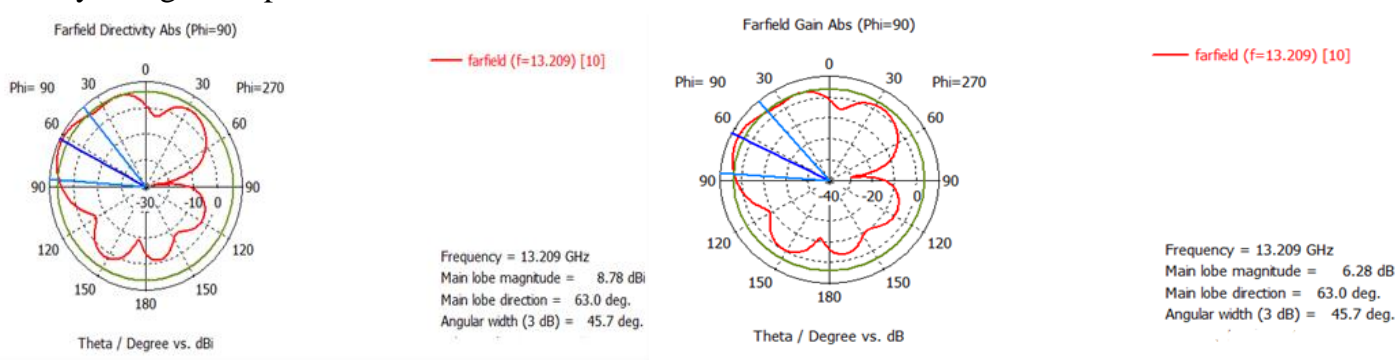

Fig. 11. Directivities and gains of SIW antenna with three circular slot

From the results, we can show that the antenna with two slots has properties that satisfy the requirement of the Ku-band. Therefore, to compare between results of SIW antennas, Fig. 12 illustrates the compression of s11 parameter for these SIW antennas.

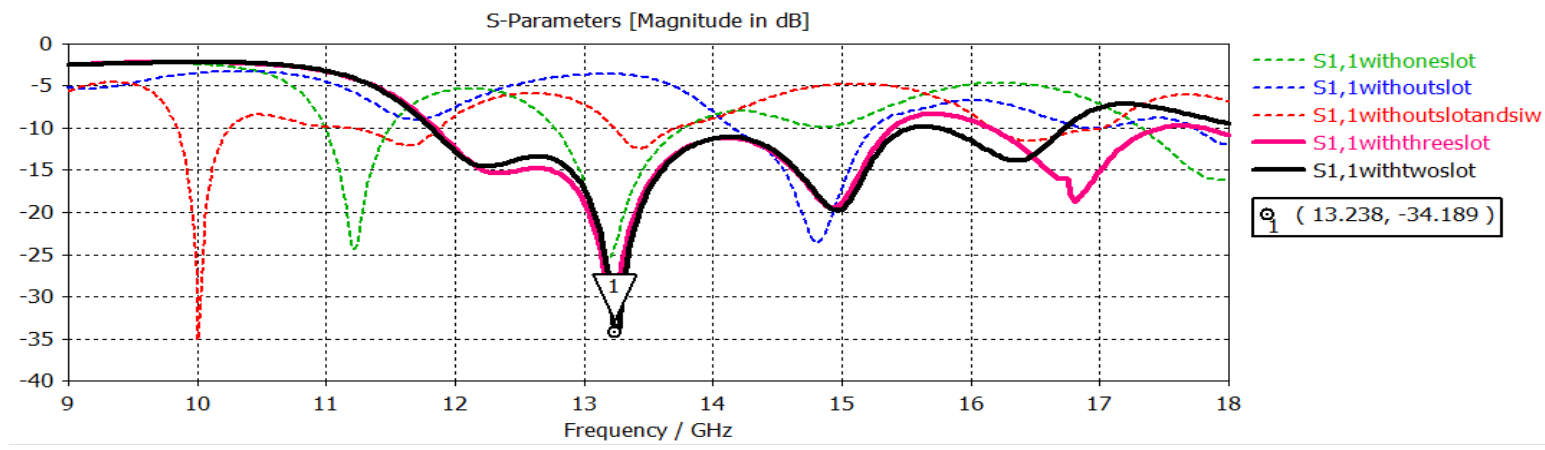

Fig. 12 S11 parameter for antennas without slots and with slots, one, two slots and three

\section{Conclusion}

According to the result of the first proposed antenna (without SIW and slot) has low gain and narrowband, when SIW technique and slots are added to the antenna structure to gives best radiation performances. Single circular slot etched on the top metallic layer as shown Fig.(7b) give triple-band resonant frequency while the gain is increased when the second slot is added, the antenna offers a wide band with higher gain reached to (4.9 GHZ). Finally when etched the third slot, the result improved slightly. This will lead to making the antenna with two circular slots satisfy the requirement of satellite application by improving the bandwidth, gain and directivity.

\section{REFERENCES}

[1] P. S. Newsletter, "Slotted Waveguide Antenna Arrays Hung Yuet Yee and Philip N . Richardson," no. December, pp. 4-8, 1982.

[2] R. R. Shah, A. Patel, and V. E. D. V. Dwivedi, "Design, development and fabrication of post coupled band pass waveguide filter at 11.2GHz for radiometer," Microw. J., pp. 1-10, 2008.

[3] A. Patel, Y. P. Kosta, N. Chhasatia, and K. Pandya, "Multiple band waveguide based microwave resonator BraodBand Microstrip Fratcal Antennas View project Phase detection system based on digital signal processing in millimeter wave interferometer for fusion plasma diagnostics View project 58 PUBLICATIONS 157 CITATIONS SEE PROFILE IEEE-INTERNATIONAL CONFERENCE ON ADVANCES IN ENGINEERING, SCIENCE AND MANAGEMENT."

[4] F. Mira, M. Bozzi, F. Giuppi, L. Perregrini, and A. Georgiadis, "Efficient design of SIW filters by 
using equivalent circuit models and calibrated space-mapping optimization," Int. J. RF Microw. Comput. Eng., vol. 20, no. 6, pp. 689-698, Nov. 2010, doi: 10.1002/mmce.20478.

[5] D. Deslandes and K. Wu, "Integrated Microstrip and Rectangular Waveguide in Planar Form," 2001.

[6] T. Djera, A. Doghri, and K. Wu, Handbook of Antenna Technologies, no. Salmon 2004. 2014.

[7] E. G. Turitsyna and S. Webb, "Simple design of FBG-based VSB filters for ultra-dense WDM transmission ELECTRONICS LETTERS 20th January 2005," Electron. Lett., vol. 41, no. 2, pp. 4041, 2005, doi: 10.1049/el.

[8] H. Y. Chien, T. M. Shen, T. Y. Huang, W. H. Wang, and R. B. Wu, "Miniaturized bandpass filters with double-folded substrate integrated waveguide resonators in LTCC," IEEE Trans. Microw. Theory Tech., vol. 57, no. 1, pp. 1774-1782, 2009, doi: 10.1109/TMTT.2009.2022591.

[9] R. Arora, S. B. Rana, and S. Arya, "Performance analysis of Wi-Fi shaped SIW antennas," AEU Int. J. Electron. Commun., vol. 94, pp. 168-178, Sep. 2018, doi: 10.1016/j.aeue.2018.07.002.

[10] Z. Xu, J. Liu, S. Huang, and Y. Li, "Gain-enhanced SIW cavity-backed slot antenna by using TE410 mode resonance," AEU - Int. J. Electron. Commun., vol. 98, pp. 68-73, Jan. 2019, doi: 10.1016/j.aeue.2018.10.039.

[11] H. A. Ali, E. Massoni, L. Silvestri, M. Bozzi, L. Perregrini, and A. Gharsallah, "Increasing the bandwidth of cavity-backed SIW antennas by using stacked cavities," Int. J. Microw. Wirel. Technol., vol. 10, no. 8, pp. 956-967, Oct. 2018, doi: 10.1017/S1759078718000478.

[12] C. Zhang, J. Wang, M. Chen, Z. Zhang, and Z. Li, "A new kind of circular polarization leaky-wave antenna based on substrate integrated waveguide," Int. J. Antennas Propag., vol. 2015, pp. 1-7, 2015, doi: $10.1155 / 2015 / 397960$.

[13] O. Caytan et al., "Half-Mode Substrate-Integrated-Waveguide Cavity-Backed Slot Antenna on Cork Substrate," IEEE Antennas Wirel. Propag. Lett., vol. 15, pp. 162-165, 2016, doi: 10.1109/LAWP.2015.2435891.

[14] Y. Cassivi, L. Perregrini, K. Wu, and G. Conciauro, "Low-Cost and High-Q Millimeter-Wave Resonator Using Substrate Integrated Waveguide Technique."

[15] K. Mahant and H. Mewada, "A novel substrate integrated waveguide (SIW) based highly selective filter for radar applications," J. Electromagn. Waves Appl., vol. 33, no. 13, pp. 1718-1725, Sep. 2019, doi: 10.1080/09205071.2019.1632747.

[16] L. Yan, W. Hong, G. Hua, J. Chen, K. Wu, and T. J. Cui, "Simulation and experiment on SIW slot array antennas," IEEE Microw. Wirel. Components Lett., vol. 14, no. 9, pp. 446-448, Sep. 2004, doi: 10.1109/LMWC.2004.832081.

[17] S. Mukherjee, A. Biswas, and K. V. Srivastava, "Broadband substrate integrated waveguide cavity-backed bow-tie slot antenna," IEEE Antennas Wirel. Propag. Lett., vol. 13, no. c, pp. 1152-1155, 2014, doi: 10.1109/LAWP.2014.2330743.

[18] A. M. Hamzah, L. Audah, and N. Alkhafaji, "H-Shaped Fractal Slots Based Highly Miniaturized Substrate Integrated Waveguide Metamaterial Bandpass Filters for C-Band Applications," vol. 86, no. March, pp. 139-158, 2020.

[19] P. E. Navamani and A. Swaminathan, "Low profile high gain circular SIW antenna for L and S band applications," Microw. Opt. Technol. Lett., vol. 61, no. 11, pp. 2482-2490, 2019, doi: 10.1002/mop.31922.

[20] M. Asaadi and A. Sebak, "High-Gain Low-Profile Circularly Polarized Slotted SIW Cavity Antenna for MMW Applications," IEEE Antennas Wirel. Propag. Lett., vol. 16, pp. 752-755, 2017, doi: 10.1109/LAWP.2016.2601900.

[21] G. Q. Luo, Z. F. Hu, W. J. Li, X. H. Zhang, L. L. Sun, and J. F. Zheng, "Bandwidth-enhanced lowprofile cavity-backed slot antenna by using hybrid SIW cavity modes," IEEE Trans. Antennas Propag., vol. 60, no. 4, pp. 1698-1704, 2012, doi: 10.1109/TAP.2012.2186226.

[22] A. Gupta, D. K. Srivastava, and J. P. Saini, "Modified e-slotted patch antenna for WLAN/Wi-Max satellite applications," TELKOMNIKA (Telecommunication Comput. Electron. Control., vol. 18, no. 1, p. 258, Feb. 2020, doi: 10.12928/telkomnika.v18i1.12959.

[23] A. Kumar and S. Raghavan, "Broadband SIW cavity-backed triangular-ring-slotted antenna for Kuband applications," AEU - Int. J. Electron. Commun., vol. 87, pp. 60-64, Apr. 2018, doi: 10.1016/j.aeue.2018.02.016.

[24] Balanis et al., "ANTENNA THEORY ANALYSIS AND DESIGN “,1938, "Modern antenna hand book / Constantine A. Balanis. , Published by John Wiley \& Sons, Inc., Hoboken, New Jersey,, 4th 
ed,2016.

[25] K. Wu, D. Deslandes, and Y. Cassivi, "The substrate integrated circuits-A new concept for highfrequency electronics and optoelectronics," 6th Int. Conf. Telecommun. Mod. Satell. Cable Broadcast. Serv. TELSIKS 2003 - Proc., vol. 1, 2003, doi: 10.1109/TELSKS.2003.1246173. 